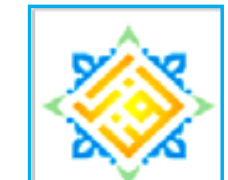

AL-FANAR

Jurnal Ilmu Al-Quran dan Tafsir
Volume 4, Nomor 2, 2021, hlm. 167-176

P-ISSN: 2622-2280 | E-ISSN: 2622-4658

https://ejurnal.iiq.ac.id/index.php/alfanar

\title{
Makna Qiradah dalam Kisah Bani Israil
}

(Aplikasi Semiotika Roland Barthes Terhadap QS Al-Baqarah [2]:65)

\author{
Aidah Mega Kumalasari \\ malaiiq15@gmail.com \\ UIN Sunan Kalijaga Yogyakarta \\ DOI: $10.33511 /$ alfanar.v4n2.167-176 \\ Submitted: 2021-06-21, Revised: 2021-07-16, Accepted: 2021-08-18
}

\begin{abstract}
This paper discusses the meaning of qiradah contained in QS. Al-Baqarah [2]:65. The meaning of qiradah has been interpreted by the community as monkeys. Even though the word qiradah is not only interpreted in an essential way. This study aims to find various meanings of qiradah with several verses using a semiotic approach. In this study, the author uses Roland Barthes' semiotic approach, namely denotation and connotation to reveal the meaning of qiradah. To achieve this goal, this research uses qualitative methods. The results of this study conclude that: First, in the linguistic system or the denotative meaning of the word qiradah, it does not only mean monkeys, but monkeys that have no shame. Second, the system of mythology or connotative meaning. The word qiradah in this system shows not the physical meaning, but the disgraceful nature that positions a person in humiliation. the interpretation of the verses of the Qur'an related to animals needs to be developed in order to expand the study of the science of interpretation of the Qur'an in order to prove the dynamic elements of the Qur'an.
\end{abstract}

Keywords: Qiradah, Semiotics, Roland Barthes, Bani Israel.

\section{Abstract}

Tulisan ini membahas tentang makna qiradah yang terdapat pada QS. AlBaqarah [2]:65. Makna qiradah selama ini diartikan oleh masyarakat sebagai kera. Padahal kata qiradah tidak hanya dimaknai secara hakiki. Penelitian ini bertujuan untuk menemukan beragam pemaknaan qiradah dengan beberapa ayat dengan menggunakan pendekatan semiotika. Dalam penelitian ini penulis menggunakan pendekatan semiotika Roland Barthes yaitu denotasi dan konotasi guna mengungkap pemaknaan qiradah. Untuk mencapai tujuan tersebut penelitian ini menggunakan metode kualitatif. Hasil penelitian ini menyimpulkan bahwa: Pertama, pada sisitem linguistik atau makna denotasi kata qiradah tidak hanya bermakna hewan kera, melainkan hewan kera yang tidak memiliki rasa malu. Kedua, sisitem mitologi atau makna konotasi. Kata qiradah pada sisitem ini menunjukkan bukan pada pemaknaan secara fisik, melainkan sifat tidak terpuji yang memposisikan seseorang pada kehinaan. penafsiran ayat-ayat Al-Qur'an yang berkaitan dengan hewan perlu dikembangkan agar dapat memperluas kajian ilmu tafsir Al-Qur'an guna membuktikan unsur dinamis dari Al-Qur'an.

Kata Kunci: Qiradah, Semiotika, Roland Barthes, Bani Israil 


\section{PENDAHULUAN}

Al-Qur'an merupakan kitab suci yang di dalamnya terdapat tema-tema pokok. Menurut Fazlur Rahman, tema-tema pokok tersebut di antaranya mengenai ketuhanan, kemanusiaan, kenabian, eskatologi, kejahatan atau setan, masyarakat muslim dan alam semesta. ${ }^{1}$ Alam semesta salah satunya membahas berbagai hal yang berkaitan dengan flora dan fauna. Nama-nama hewan (fauna) di dalam Al-Qur'an disebutkan secara terbuka dalam beberapa surat. Hewan-hewan yang disebutkan dalam AlQur'an di antaranya: hewan ternak (sapi, unta, kambing dan kerbau) yang terdapat di dalam QS. al-An'am [6]:142-144, binatang buas QS. al-Maidah [5]:3, burung QS. alBaqarah [2]:260, anak sapi QS. al-A'raf [7]:148, himar QS. al-Baqarah [2]:259, kuda QS. al-Isra [17]: 64, semut QS. an-Naml [27]:18, anjing QS. al-Khaf [18]:9-18, babi QS. al-An'am [6]:145, kera QS. al-Baqarah [2]:65, laba-laba QS. al-Ankabut[29]:41. ${ }^{2}$ Diantara nama-nama hewan tersebut yang menjadi fokus pembahasan artikel ini adalah penyebutan qiradah (kera) di dalam Al-Qur'an.

Kata qiradah di dalam Al-Qur'an menceritakan tentang kisah Bani Israil yang tinggal di pesisir laut Qazlum. Mereka dikutuk menjadi kera disebabkan karena mereka melanggar ketetapan Allah SWT. Pelanggaran yang mereka lakukan berupa mengabaikan larangan mencari ikan pada hari Sabtu (Hari Sabt). ${ }^{3}$ Kutukan yang ditetapkan kepada mereka mendapatkan sorotan dari beberapa mufassir. Para mufasir memiliki perbedaan pendapat dalam menafsirkan kata qiradah. Sebagian mufasir menafsirkan kata qiradah bermakna hukuman secara fisik. Sementara itu sebagian mufasir lainya menafsirkan hukman secara non fisik.

Terdapat beberapa penelitian sebelumnya yang berkaitan dengan pemaknaan qiradah dalam Al-Qur'an, di antaranya: artikel yang ditulis oleh Kamarul Azmi Jasmi, artikel yang berjudul "Bani Israil dan Sumpah Menjadi Kera: Al-Baqarah [2]:62-66." Artikel ini membahas mengenai pelajaran penting yang harus dipahami dari kisah Bani Israil yaitu pentingnya syariat Islam, menepati janji dan larangan melanggar perintah Allah SWT. ${ }^{4}$ penelitian selanjutnya oleh oleh Raja Inal Hasibuan. Artikel ini membahas penafsiran Aidh Al-Qarni tentang QS. Al-Baqarah [2]:65 di dalamnya ia menafsirkan bahwa Bani Israil melanggar janjinya kepada Allah SWT dengan bermaksiat dan mencari ikan pada hari sabtu. Kemudian Allah SWT mengutuk mereka dalam bentuk kera dan babi baik secara fisik maupun sifatnya ${ }^{5}$. Selanjutnya Artikel yang ditulis oleh Rica Revita Putri. Artikel tersebut menjelaskan tentang nilai Akhlak yang terdapat pada kisah Ashab Al-Sabt. Diantaranya; bersikap sabar, jujur, bertakwa kepada Allah SWT dan Rasul. ${ }^{6}$

${ }^{1}$ M. Yusran Asmuni, Dirasah Islamiyah I: Pengantar Studi Al-Qur'an Hadits Figh Dan Pranata Sosia., 1997, h. 43.

${ }^{2}$ Masyhuri Putra, “Mengungkap Kemukjizatan Ilmiah Dalam Al-Qur'an,” Jurnal An-Nur 4, no. 2 (2015): h. 179.

${ }^{3}$ Rica Ravita Putri, "Nilai-Nilai Akhlak Pada Kisah Ashab Al-Sabt Dalam Al-Qur'an," UIN Sultan Syarif Kasim Riau, 2020, h. 34.

${ }^{4}$ Jasmi Kamarul Azmi, "Bani Israil Dan Sumpahan Menjadi Kera: Al-Baqarah (2:62-66)," Universiti Teknologi Malaysia, 2018.

${ }^{5}$ Raja Inal Hasibuan, "Kutukan Dalam Al-Qur'an (Studi Tafsir Al-Muyassar Surah Al-Baqarah Ayat 65 dan Surah Al-A'raf Ayat 166 Karya Aidh Al-Qarni)," UIN Sumatera Utara, 2019.

${ }^{6}$ Putri, "Nilai-Nilai Akhlak Pada Kisah Ashab Al-Sabt Dalam Al-Qur'an." 
Sementara itu pada artikel ini, penulis memaparkan makna qiradah yang terdapat dalam QS. Al-Baqarah [2]:65 dengan menggunakan teori semiotika. Dalam hal ini penulis menggunakan semiotika Roland Barthes karena semiotika Roland Barthes memiliki metode analisis struktural yang jelas dalam kritik teks termasuk di antaranya kritik teks dalam Al-Qur'an. Hal lain yang menjadi sebab penggunaan semiotika Roland Barthes karena kata qiradah dalam QS. Al-Baqarah [2]:65 memiliki simbol kebahasaan dan pesan yang dapat diinterpretasikan.

Tujuan dari penulisan artikel ini terfokus pada bagaimana kata qiradah QS. AlBaqarah [2]:65 dijelaskan dalam beberapa kitab tafsir?. Dan juga bagaimana semiotika Roland Barthes membaca fenomena Qiradah ini?. Adapun manfaat dari penulisan artikel ini untuk memberikan gambaran baru mengenai perkembangan kajian studi Al-Qur'an. Selain itu penelitian ini juga bertujuan agar umat Islam memahami ayat Al-Qur'an tidak hanya secara tekstual saja namun perlu adanya penelitian secara mendalam.

Untuk itu, pendekatan yang digunakan dalam penelitian ini adalah pendekatan semiotika Roland Barthes. Pendekatan semiotika ini terfokus pada pemaknaan denotasi sebagai signifikan tingkat pertama dan konotasi sebagai tingkat kedua. ${ }^{7}$ Pendekatan tersebut mampu mempermudah peneliti dalam menganalisis berbagai tanda yang terdapat dalam sebuah teks maupun non teks yang diteliti. Dalam hal ini penulis menganalisis kata qiradah sebagai suatu tanda yang terdapat dalam Al-Qur'an dengan menggunakan petunjuk kitab-kitab kamus. Kemudian penulis memperjelas analisis dengan memaparkan penjelasan para mufasir dalam beberapa kitab tafsir. setelah itu penulis membandingkan pendapat-pendapat para mufasir dengan teori denotasi dan konotasi. Dengan demikian dapat dihasilkan berbagai pemaknaan qiradah melalui pembacaan atau pendekatan semiotika Roland Barthes.

\section{SEMIOTIKA ROLAND BARTHES}

Roland Barthes lahir pada tahun 1915 di Prancis tepatnya di daerah Cherbough, Manche. Barthes merupakan ilmuwan yang terkenal dan aktif sebagai penemu dan pembimbing dalam beberapa bidang. Di antaranya dalam bidang Bahasa, Sastra, Budaya dan juga Media. Barthes merupakan alumni Universitas Paris di jurusan French Literature and Classisc. Barthes aktif dalam mengajar Sastra Prancis, ia tercatat pernah mengajar di Rumania dan Mesir. ${ }^{8}$ Selain itu Barthes juga aktif dalam dunia penelitian khususnya penelitian sosiologi dan leksiologi. Dalam penelitian tersebut Barthes bergabung dalam tim The Center National de Recherche Scientifique. Dalam bidang semiologi literal, Barthes diangkat sebagai profesor di College de France. Pada tahun 1980 Barthes mengalami kecelakaan yang merengut nyawanya. ${ }^{9}$

Semiotika adalah ilmu yang membahas mengenai tanda-tanda dalam berbagai fenomena baik sosial-budaya juga sastra. ${ }^{10}$ Teori semiotika Roland Barthes terkenal

\footnotetext{
${ }^{7}$ Ninuk Lustyantie, "Pendekatan Semiotik Model Roland Barthes Dalam Karya Sastra Prancis," Seminar Nasional FIB UI, 2012, h. 3.

8 Setianto, "Makna Visual Azan Magrib Di ANTV, TRANS7, Dan KOMPASTV Analisis Semiotika Roland Barthes," Institut Agama Islam Negeri Purwokerto, 2020, h. 20.

${ }^{9}$ Husni Mubarak, "Mitologi Bahasa Agama: Analisis Kritis dari Semiologi Roland Barthes," UIN Syarif Hidayatullah Jakarta, 2007, h. 15.

${ }^{10}$ Rachmat Djoko Pradopo, "Semiotika: Teori, Metode, dan Penerapannya dalam Pemaknaan Sastra," no. 10 (1999): h. 76.
} 
Makna Qirodah dalam Kisah Bani Israil

(Aplikasi Semiotika Roland Barthes Terhadap QS Al-Baqarah [2]:65)

dengan dua level pertanda yang menghasilkan makna. Level tersebut yaitu denotasi dan konotasi. Tidak hanya sampai pada tataran dua konsep tanda saja, Barthes juga melihat peranan yang aktif dari pembaca atau pengguna. Barthes menggangap peran pembaca dalam memaknai tanda tersebut akan memunculkan suatu pengertian baru yang lebih jelas. ${ }^{11}$

Denotasi adalah level makna deskriptif dan literal yang ada pada suatu budaya atau disebut juga sebagai makna yang tampak. Misalnya, 'tikus' merupakan hewan berkaki empat dan biasanya berwarna hitam, hidup dan mencari makan di tempat yang kotor. Sedangkan level makna kedua yaitu konotasi merupakan makna yang terbentuk dengan mengaitkan penanda dengan aspek-aspek kultural yang lebih luas (keyakinan, sikap, kerangka kerja, dan ideologi suatu formasi sosial). ${ }^{12}$ Jadi, 'tikus' bisa bermakna konotatif yaitu koruptor atau manusia yang rakus dan berbuat kotor.

Makna konotasi yang merupakan makna hasil dari stimulus dan respon dari nilainilai yang mengandung emosional juga sering diidentikkan dengan operasi ideologi atau yang disebut sebagai mitos. Hal ini berfungsi untuk mengungkapkan serta memberikan pembenaran bagi nilai-nilai dominan yang berlaku dalam suatu periode tertentu. Jadi, dalam konsep Barthes, tanda konotatif tidak sekedar memiliki makna tambahan namun juga mengandung kedua bagian tanda denotatif yang melandasi keberadaannya. Dan hal inilah yang membedakan sekaligus menyempurnakan semiologi Saussure yang dikenal dengan signifikansi dua tahap (Two order of signification). ${ }^{13}$

Gambar Konsep Semiologi Roland Barthes

\begin{tabular}{|c|c|}
\hline Signifier (penanda) & Signified (petanda) \\
\hline \multicolumn{2}{|c|}{ Denotative sign (tanda denotatif) } \\
\hline $\begin{array}{c}\text { Connotative signifier } \\
\text { (penanda konotatif) }\end{array}$ & $\begin{array}{c}\text { Connotative signified } \\
\text { (petanda konotatif) }\end{array}$ \\
\hline \multicolumn{2}{|c|}{ Connotative sign (tanda konotatif) } \\
\hline
\end{tabular}

Barthes berpendapat bahwa mitos melayani fungsi ideologi naturalisasi. Artinya, mitos melakukan naturalisasi budaya. Dengan kata lain, mitos membuat budaya, nilainilai sejarah, kebiasaan dan keyakinan yang dominan terlihat "naturale, normal, abadi, masuk akal, objektif dan benar secara apa adanya. Ideologi yang tercermin dalam mitos akan selalu ada selama kebudayaan itu ada. Ia merupakan suatu ekspresi budaya yang diwujudkan melalui berbagai kode yang masuk ke dalam teks dalam bentuk penandapenanda penting, seperti tokoh, latar, sudut pandang, dan lain sebagainya.

\section{MAKNA QIRADAH DALAM PERSPEKTIF SEMIOTIKA ROLAND BARTHES}

Di dalam Al-Qur'an kata qiradah disebutkan sebanyak tiga kali, yakni:

\footnotetext{
${ }^{11}$ Antonius M Birowo, Metode Penelitian Komunikasi (Yogyakarta: Gitanyali Bungin, 2004).

${ }^{12}$ Chris Barker, Curtural Studies: Teori Dan Praktik, Kesebelas (Bantul: Kreasi Wacana, 2018), hlm. 74 .

${ }^{13}$ Alex Sobur, Semiotika Komunikasi (Bandung: PT. Remaja Roasdakarya, 2016), hlm. 69.
} 
QS. Al-Baqarah [2]:65

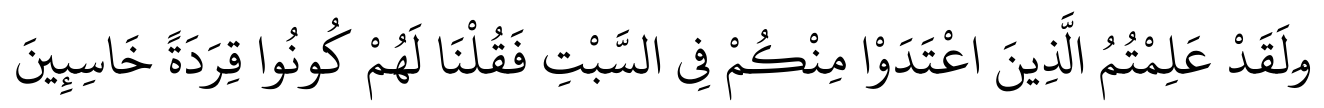

"Dan Sesungguhnya telah kamu ketahui orang-orang yang melanggar diantaramu pada hari Sabtu, lalu Kami berfirman kepada mereka: "Jadilah kamu kera yang hina". (QS. Al-Baqarah [2]:65)

\section{QS. Al-Ma'idah [5]:60}

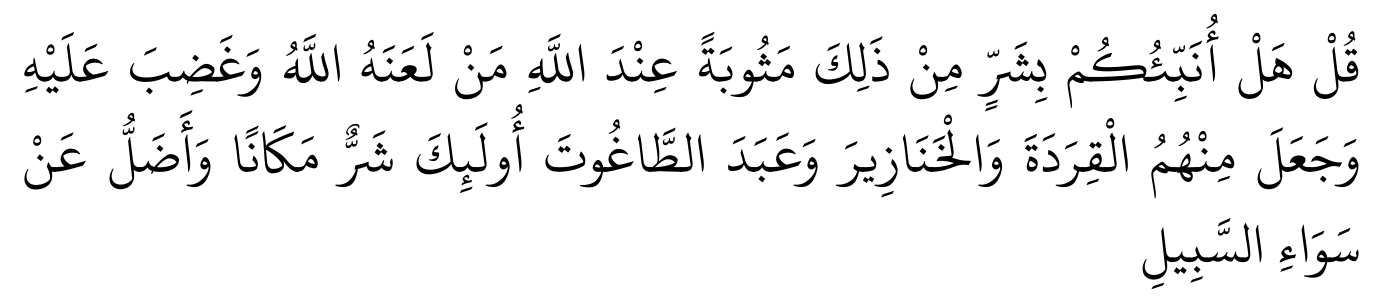

"Katakanlah: "Apakah akan aku beritakan kepadamu tentang orang-orang yang lebih buruk pembalasannya dari (orang-orang fasik) itu disisi Allah, Yaitu orangorang yang dikutuki dan dimurkai Allah, di antara mereka (ada) yang dijadikan kera dan babi dan (orang yang) menyembah thaghut?". mereka itu lebih buruk tempatnya dan lebih tersesat dari jalan yang lurus". (QS. Al-Ma'idah [5]:60)

QS. Al-A'raf [7]:163-167

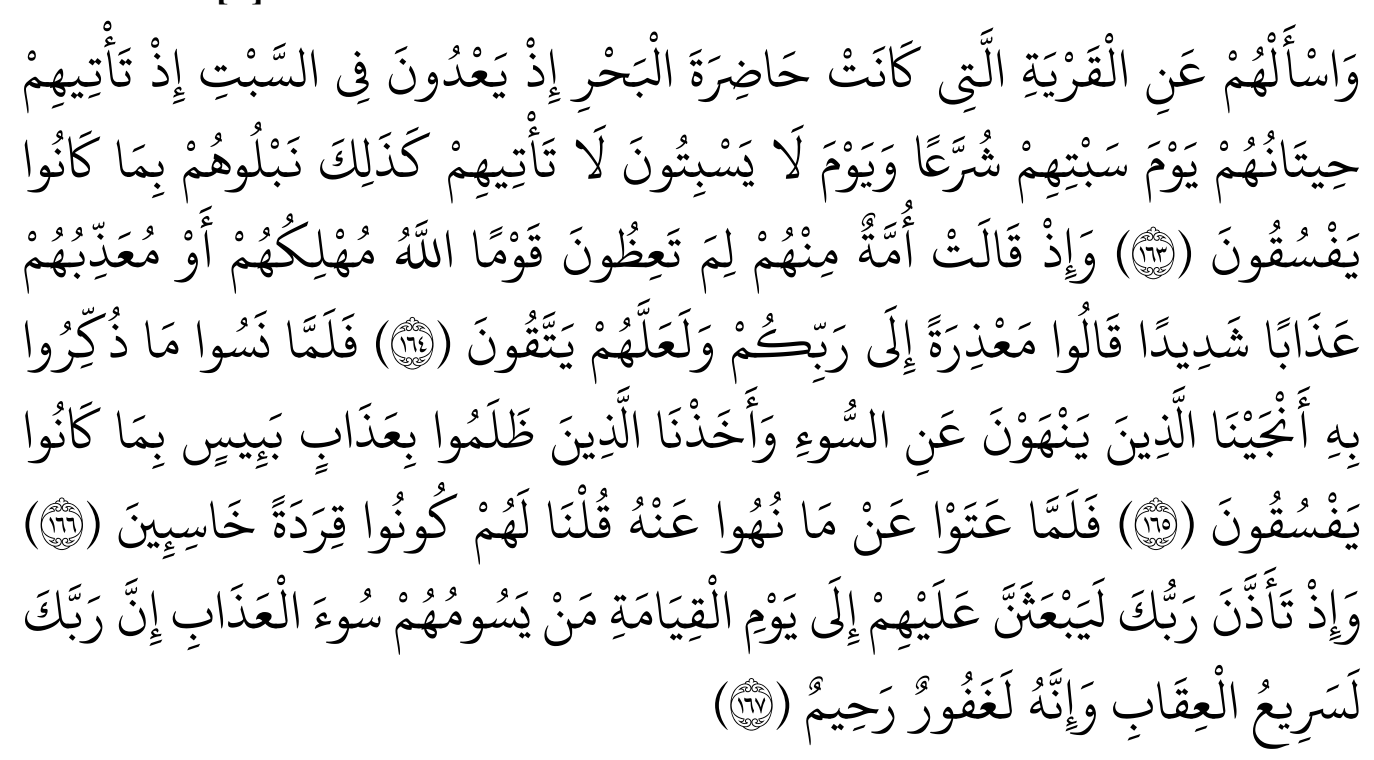

"Dan Tanyakanlah kepada Bani Israil tentang negeri yang terletak di dekat laut ketika mereka melanggar aturan pada hari Sabtu, di waktu datang kepada mereka ikan-ikan (yang berada di sekitar) mereka terapung-apung di permukaan air, dan di hari-hari yang bukan Sabtu, ikan-ikan itu tidak datang kepada mereka. Demikianlah Kami mencoba mereka disebabkan mereka Berlaku fasik. Dan (ingatlah) ketika suatu umat di antara mereka berkata: "Mengapa kamu menasehati kaum yang Allah akan membinasakan mereka atau mengazab mereka dengan azab yang Amat keras?» mereka menjawab: "Agar Kami mempunyai alasan (pelepas tanggung jawab) kepada Tuhanmu, dan supaya mereka bertakwa. Maka tatkala mereka melupakan apa yang diperingatkan kepada mereka, Kami selamatkan orang-orang yang melarang dari perbuatan jahat dan Kami timpakan kepada orang-orang yang zalim siksaan yang keras, disebabkan mereka selalu berbuat fasik. Maka tatkala mereka bersikap sombong terhadap apa yang dilarang mereka mengerjakannya, Kami katakan kepadanya: 
Makna Qirodah dalam Kisah Bani Israil

(Aplikasi Semiotika Roland Barthes Terhadap QS Al-Baqarah [2]:65)

"Jadilah kamu kera yang hina. Dan (ingatlah), ketika Tuhanmu memberitahukan, bahwa Sesungguhnya Dia akan mengirim kepada mereka (orang-orang Yahudi) sampai hari kiamat orang-orang yang akan menimpakan kepada mereka azab yang seburuk-buruknya. Sesungguhnya Tuhanmu Amat cepat siksa-Nya, dan Sesungguhnya Dia adalah Maha Pengampun lagi Maha Penyayang”

Namun pada penelitian ini penulis hanya membahas kata qiradah dalam QS. AlBaqarah [2]:65.

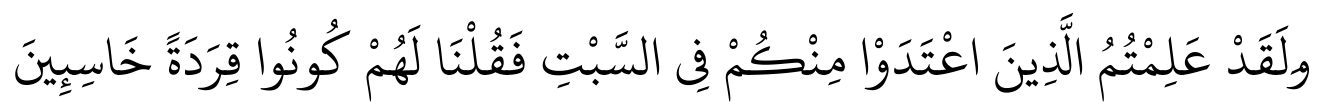

"Dan Sesungguhnya telah kamu ketahui orang-orang yang melanggar diantaramu pada hari Sabtu, lalu Kami berfirman kepada mereka: «Jadilah kamu kera yang hina".

Al-Qattan mengkategorikan ayat diatas sebagai ayat kisah yang berkaitan dengan masa lalu. Selain itu ayat di atas masuk dalam bagian ayat kutukan (la'ana). La'ana berarti atau diartikan terkutuk, terlaknat atau tersingkir. Hal yang demikian disebabkan karena manusia mengingkari atau durhaka atas perintah, janji, dan larangan Allah SWT.

\section{Sistem Lingustik}

Tahap awal dari teori semiotika Roland Barthes adalah sistem lingustik yang berarti makna denotasi. Dalam hal ini analisis dilakukan secara tekstual mengeni kata qiradah yang berarti kera dan juga melihat makna qiradah tersebut di beberapa kamus serta pendapat para mufasir.

Kata قِرَدَّة berasal dari kata قَرَدَ bunyi harakat fathah, Ra dengan bunyi harakat fathah dan Dal dengan bunyi harakat fathah, yang kemudian berkembang menjadi قِ قِرَدَ yakni huruf Qof dengan bunyi harokat kasroh, Ra dengan bunyi harokat fatha, Dal dengan bunyi harokat fathah dan tambah huruf Ta Marbutho dengan bunyi harokat fathatain. Secara morfologi kata قِرَدَة القِرْدُ merupakan kalimat isim bentuk jama' dari bermakna kera. Semantara itu dalam KBBI kata kera memiliki sinonim kata monyet yang memiliki arti binatang menyusui (mamalia) bentuk tubuh mirip manusia, berbulu dari ujung kepala sampai dengan ujung kaki, memiliki ekor dan pada umumnya pemakan buah-buahan dan

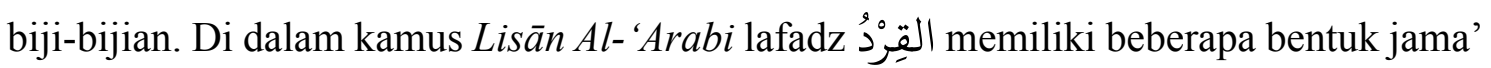

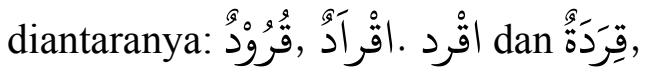

Ibnu Manzur menjelaskan kata qirodah yang terdapat dalam surat Al-Baqarah di atas, memiliki dua kedudukan dalam susunan ilmu nahwu pertama, kata قِرَدَّة merupakan khobar pertama dari kata كُونُو خَسِنِين dan khobar kedua adalah kata sehingga lafadz diatas bermakna "jadilah kalian kera-kera, jadilah kalian orang-orang yang hina". Kedua, kata خَسِئِين dijadikan sifat dari kata قِرَدَة yang maknanya menjadi sempit yakni “jadilah kamu kera-kera yang hina". Ibnu Manzur menambahkan penempatan kedudukan susunan pertama dari kalimat di atas merupakan penembatan susunan yang paling cocok serta memiliki makna yang luas.

Ibnu Katsir dalam tafsirnya menjelaskan bahwa orang-orang yahudi kaum Bani Israil melanggar janji Allah SWT dengan mencari ikan di hari Sabtu, yang kemudian 
Allah mengutuk mereka mengubah wajah, fisik dan perilaku mereka menjadi kera.

"Ibn Abbas menjelaskan:”Maka Allah SWT mengubah sebagian mereka menjadi kera, dan sebagian mereka menjadi babi. Diduga bahwa para pemuda dari kaum tersebut menjadi kera sedangkan orang-orang tuanya menjadi babi. Dan mereka hidup dimuka bumi kecuali hanya tiga hari saja, tidak makan tidak minum serta tidak melahirkan keturunan. Sebab, Allah telah menciptakan kera, babi dan mahluk lainya sebelumnya. Demikian Allah SWT mengubah sesuatu sesuai dengan kehendak-Nya pula".

Dalam tafsir Al-Qurtubi dijelaskan Bani Israil mereka melanggar perintah yang berkaitan dengan hari Sabtu, yakni dengan memancing ikan paus di hari Sabtu dengan tujuan mencari jalan untuk menghalalkan apa yang sudah diharamkan Allah SWT.

"Asyhab meriwayatkan ungkapan Imam Malik: Ibn Rumman mengatakan bahwa seseorang dari mereka mengambil seutas tali yang dijadikan perangkap dan dilemparkan pada ekor ikan paus, sedangkan ujung tali lainya diikat dan ditinggalkan begitu saja hingga hari Ahad. Kemudian orang lain mengikuti dan tidak langsung dihukum ketika melakukanya, hingga banyak orang yang memancing ikan paus dan menjualnya ke pasar. Kemudian ada satu orang memamerkan hasil tangkapanya dan langsung ditentang oleh sekelompok, sebagian kelompok ini langsung memisahkan diri dikarenakan tidak sudi tinggal satu kampung dengan mereka. Kelompok ini kemudian membuat tembok pemisah dari orang-orang sesat itu, kemudian kelompok ini melihat kebalik tembok dan mereka terkejut karena orang-orang tersesat telah berubah menjadi kera dan babi secara fisik".

M. Quraish Shihab menjelaskan dalam tafsirnya, tafsir Al-Misbah mengenai ayat diatas bahwa mereka melanggar ketentuan Allah pada hari sabtu, dan hari sabtu adalah hari bagi orang-orang Yahudi untuk beribadah dan membebaskan diri dari aktivitas duniawi. Mereka dilarang untuk mengail ikan di hari Sabtu, sebagian dari mereka mempunyai cara licik yakni tidak mengail ikan namun membendung ikan dengan membuat kolam sehingga air dan ikan masuk kedalam kolam tersebut, karena hal itu Allah SWT mengutuk mereka menjadi kera dan babi baik secara fisik maupun sifatnya.

Dari beberapa penjelasan di atas dapat disimpulkan bahwa makna dari kata qiradah dalam QS. Al-Baqarah [2]:65, qiradah merupakan kutukan bagi kaum Bani Israil karena menentang, mendustai dan berusaha untuk menghalalkan apa yang sudah diharamkan Allah SWT. Kutukan tersebut dengan berubahnya bentuk fisik dan sifat kaum Bani Israil menjadi kera dan juga babi. Kata qiradah menjadi penanda dan kera sebagai petanda.

\section{Sistem Mitologi}

Tahap selanjutnya yakni tahap kedua dari teori semiotika Roland Barthes adalah sistem mitologi atau makna konotasi, dengan cara mengali makna qiradah dari konotasinya sehingga didapatkan makna yang lebih luas.

Asbab Nuzul QS. Al-Baqarah [2]: 65 di dalam tafsir Ibnu Katsir dijelaskan diriwayatkan dari Duad ibnu Abul Husain, dari Ikrimah, bahwa Ibnu Abbas r.a. pernah mengatakan:

"Sesungguhnya hal yang difardlukan oleh Allah kepada kuam Bani Israil adalah sama dengan hari yang difardlukan kepada kalian, yaitu hari Jum'at. Tetepi mereka menggantinya menjadi hari Sabtu, lalu mereka menghormati hari Sabtu (sebagai penganti hari Jum'at) dan mereka meninggalkan apa-apa yang diperintahkan 
kepadanya. Tetepi setelah mereka membangkang dan hanya menetapi hari Sabtu, Allah menguji mereka dengan hari Sabtu itu dengan diharamkan atas mereka banyak hal yang telah dihalalkan bagi mereka selian hari Sabtu yakni Allah mengharamkan mereka mencari ikan dan memekan ikan pada hari tersebut".

Riwayat yang paling kuat yakni kutukan tersebut berupa berubahnya bentuk fisik dan perilaku. Hal ini sesuai dengan pendapat ulama. Sebagaimana penjelasan Quraish Sihab bahwa kata kera ini memiliki makna yang lebih dalam dibandingkan yang bermakna hewan saja. Kata kera disini memperlihatkan sifat dari hewan tersebut. Kutukan menjadi kera disebabkan kera merupakan hewan yang selalu menampakkan auratnya, bentuk bulu dan kulit yang kontras menyebabkan aurat dari kera sangat terlihat sehingga kera disini tidak memiliki rasa malu. Kemudian babi merupakan hewan tanpa rasa cemburu sehingga jika pasangannya digauli oleh babi lain, hal ini tidaklah menjadi masalah bagi babi tersebut. Disini Quraish Shihab menekankan bahwa bukan pada bentuk fisik dari kera tersebut tetepi sifat dari kera itu.

Dari penjelasan kontesktual QS. Al-Baqarah [2]:65 ayat ini berkaitan erat dengan ayat sebelum yang menjelaskan mengenai ingkar janji mereka dan ayat sesudahnya yang menjelaskan tentang pelajaran atau hikmah yang dapat diambil dari kisah ayat tersebut, yakni ayat ke 64 dan 66,

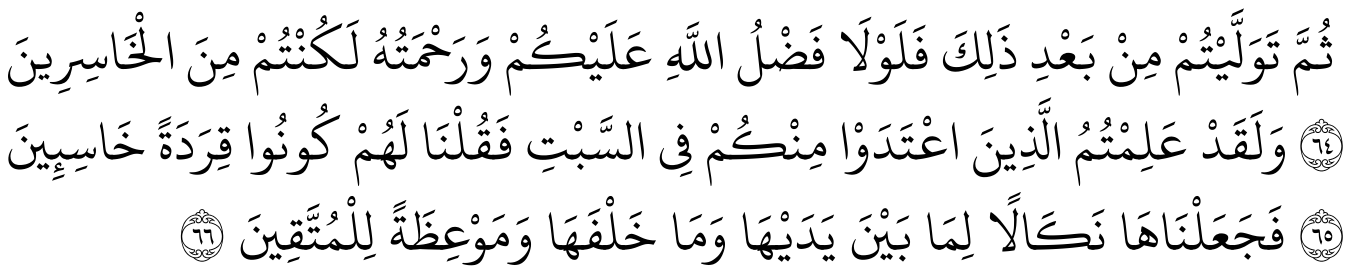

"Kemudian kamu berpaling setelah (adanya perjanjian) itu, Maka kalau tidak ada karunia Allah dan rahmatNya atasmu, niscaya kamu tergolong orang yang rugi. Dan Sesungguhnya telah kamu ketahui orang-orang yang melanggar diantaramu pada hari Sabtu lalu Kami berfirman kepada mereka: "Jadilah kamu kera yang hina". Maka Kami jadikan yang demikian itu peringatan bagi orang-orang dimasa itu, dan bagi mereka yang datang Kemudian, serta menjadi pelajaran bagi orang-orang yang bertakwa."

Yang perlu diketahui bahwa lafadz qiradatan khosi'in merupakan kutukan yang menitik beratkan pada sifat dari kera tersebut, alasan kenapa hewan kera yang dijadikan sebagai kutukan, dikarenakan tidak dimilikinya sifat malu. Berikut adalah tabel penerapan dari teori semiotika Roland Barthes terhadap QS. al-Baqarah [2]: 65

\begin{tabular}{|c|c|c|}
\hline \multirow[b]{2}{*}{ LINGUISTIK } & $\begin{array}{l}\text { 1. Signifier } \\
\text { (Penanda I) } \\
\text { Qiradah }\end{array}$ & $\begin{array}{l}\text { 2. Signified } \\
\text { (Patanda I) } \\
\text { Hewan Kera }\end{array}$ \\
\hline & $\begin{array}{c}\text { 3. TANDA I } \\
\text { (Penanda II) } \\
\text { Qiradah dengan } \\
\text { makna hewan kera }\end{array}$ & $\begin{array}{l}\text { (Petanda II) } \\
\text { Tidak memiliki sifat } \\
\text { malu }\end{array}$ \\
\hline MITOLOGI & \multicolumn{2}{|c|}{$\begin{array}{c}\text { TANDA II } \\
\text { Orang yang tidak memiliki sifat atau rasa } \\
\text { malu }\end{array}$} \\
\hline
\end{tabular}


Dari penjelasan dan pemaran kata konsep kata qiradah dalam QS. Al-Baqarah [2]:65 dapat disimpulkan teori semiotika tahap pertama yakni kajian linguistik kata qiradah memiliki makna denotasi hewan kera yang tidak memiliki rasa malu. Karena hewan kera tidak pernah menutupi auratnya, hal ini berkaitan antara warna bulu dan kulit kera sangatlah kontras sehingga warna kulit terlihat begitu jelas. Kemudian tahapan kedua yakni mitologi, makna konotasi yang didapatkan adalah orang yang tidak memiliki sifat atau rasa malu, tidaklah menjadi masalah fisik dari seseorang tersebut, justru sifatlah yang menjadi inti permasalahan sehingga menyebabkan kutukan tersebut, sifat yang diperlihatkan dari kera ini ialah sifat rakus atau merasa kurang akan pemberian yang telah diberikan Allah SWT. Sehingga sifat rakus tersebut membawa seseorang untuk menghalalkan segala cara dan hanya mementingkan diri sendiri sehingga mereka mengupayakan segala hal agar ia mendapatkan apa yang ia inginkan terlebih menghalalkan apa yang sudah diharamkan Allah SWT.

Dewasa ini, sering kita melihat atau mendengar fenomena adanya sikap-sikap yang berkaitan dengan sifat rakus tersebut. Seorang pejabat mengambil uang rakyat hanya untuk memenuhi kebutuhan mewahnya secara pribadi, padahal ia atau apa yang ia lakukan telah melanggar perintah Allah SWT, namun ia tetap melakukan hal tersebut karna ia hanya memikirkan dirinya sendiri. Kejadian baru-baru ini pasien Covid-19 meroket tinggi, sehingga menyebabkan kekhawatiran pada masyarakat, namun hal yang dilakukan justru sangat disayangkan, mereka berbondong-bondong mendatangi swalayan dan saling berebut dan mengambil susu steril (susu tersebut dipercaya dapat menjaga imunitas tubuh) dalam jumlah banyak, sehingga sebagian dari mereka tidak mendapatkanya. Padahal dalam menjaga imunitas tubuh tidaklah hanya perpatokan pada apa yang kita konsumsi namun juga cara perfikir dengan tetap syukur atas apa yang sudah diberikan Allah SWT.

Dari penjelasan diatas pelajaran yang dapat kita ambil, yakni jangalah melanggar apapun yang sudah ditetapkan Allah SWT. Terlebih berusaha mencari cara menghalalkan apa yang sudah Allah haramkan karna hal tersebut hanya akan berbuah kerugian, kesengsaraan dan lain-lain. Allah SWT. tidak akan menelantarkan hambanya sekecil apapun itu. Allah telah mengatur dengan sempurna rizki baik dalam bentuk makanan, minuman, barang dan lain-lain sehingga hambanya tidak akan meresa kekurangan.

\section{PENUTUP}

Kata qiradah dalam QS Al-Baqarah [2]:65 dalam bahasa Indonesia berarti monyet atau kera. Dalam KBBI dijelaskan kera memiliki sinonim kata monyet yang memiliki arti binatang menyusui (mamalia) bentuk tubuh mirip manusia, berbulu dari ujung kepala sampai dengan ujung kaki, memiliki ekor dan pada umumnya pemakan buahbuahan dan biji-bijian. Kata qiradah juga disebutkan dalam surat lain yakni surat Al-Ma'idah [5:60] dan surat Al-A'raf [7:166].

Dalam teori semiotka Rolan Barthes, kata qiradah pada tahap awal yakni makna denotasi memiliki makna kera atau monyet yang tidak memiliki rasa malu. Kemudian tahapan kedua yakni mitologi, makna konotasi yang didapatkan adalah orang yang tidak memiliki sifat atau rasa malu. Rasa malu inilah yang menimbulkan sifat-sifat buruk lainya, seperti sifat rakus. Sifat rakus atau merasa kurang akan pemberian yang telah diberikan Allah SWT, sehingga sifat rakus tersebut membawa seseorang untuk menghalalkan segala cara dan hanya mementingkan diri sendiri sehingga 
mereka mengupayakan segala hal agar ia mendapatkan apa yang ia inginkan terlebih menghalalkan apa yang sudah diharamkan Allah SWT.

\section{DAFTAR PUSTAKA}

Abdullah, M. Tafsir Ibnu Katsir Jilid 2. Jakarta: Pustaka Imam Asy-Syafi'i, 2007.

Asmuni, M. Yusran. Dirasah Islamiyah I : Pengantar Studi Al-Qur'an Hadits Figh Dan Pranata Sosia., 1997.

Barker, Chris. Curtural Studies: Teori Dan Praktik. Kesebelas. Bantul: Kreasi Wacana, 2018.

Birowo, Antonius M. Metode Penelitian Komunikasi. Yogyakarta: Gitanyali Bungin, 2004.

Hasibuan, Raja Inal. "Kutukan Dalam Al-Qur'an (Studi Tafsir Al-Muyassar Surah AlBaqarah Ayat 65 dan Surah Al-A'raf Ayat 166 Karya Aidh Al-Qarni)." UIN Sumatera Utara, 2019.

Kamarul Azmi, Jasmi. "Bani Israil Dan Sumpahan Menjadi Kera: Al-Baqarah (2:6266)." Universiti Teknologi Malaysia, 2018.

Lustyantie, Ninuk. "Pendekatan Semiotik Model Roland Barthes Dalam Karya Sastra Prancis.” Seminar Nasional FIB UI, 2012.

Mandzur, Ibnu. Lisan Al-Arab. Juz 12. Kairo: Darul Hadis, 2002.

Mubarak, Husni. "Mitologi Bahasa Agama: Analisis Kritis dari Semiologi Roland Barthes." UIN Syarif Hidayatullah Jakarta, 2007.

Munawwir, A. W. Kamus Al-Munawwir Indonesia Dan Arab. Surabaya: Pustaka Progressif, 2007.

Pradopo, Rachmat Djoko. "Semiotika: Teori, Metode, dan Penerapannya dalam Pemaknaan Sastra," no. 10 (1999): 9.

Putra, Masyhuri. “Mengungkap Kemukjizatan Ilmiah Dalam Al-Qur'an.” Jurnal An-Nur 4, no. 2 (2015).

Putri, Rica Ravita. "Nilai-Nilai Akhlak Pada Kisah Ashab Al-Sabt Dalam Al-Qur'an." UIN Sultan Syarif Kasim Riau, 2020.

Al-Qattan, Khalil Manna'. Studi Ilmu-Ilmu Qur'an, Terj. Mudzakir AS. 9. Bogor: Pustaka Litera Antar Nusa, 2009.

Qurthubi, Muhammad bin Ahmad Abi Bakr Abi 'Abdullah al-. Tafsir Al-Qurthubi, Judul Asli Al Jami' Li Ahkam Al Qur'an. Terj. Muhyiddin Masridha. Jakarta Selatan: Pustaka Azzam, 2009.

Rahmat, Pupu Saeful. "Penelitian Kualitatif.” Junal Equilibrium 5, no. 9 (2009).

Setianto. "Makna Visual Azan Magrib Di ANTV, TRANS7, Dan KOMPASTV Analisis Semiotika Roland Barthes." Institut Agama Islam Negeri Purwokerto, 2020.

Shihab, Quraish. M. Tafsir Al-Misbah. Vol. Cet V. Jilid 1. Jakarta: Lentera Hati, 2005.

Sobur, Alex. Semiotika Komunikasi. Bandung: PT. Remaja Roasdakarya, 2016.

Suwendra, I Wayan. Metodelogi Penelitian Kualitatif Dalam Iilmu Sosial, Pedidikan, Kebudayaan dan Keagamaan. Cet. Pertama. Bandung: Nilacakra, 2018. $\underline{\text { www.kbbi.kemen }}$ 